\title{
BIAFRA NAS PÁGINAS DA REVISTA VEJA (1968-1970): ENTRE IMAGENS, DISCURSOS E REPRESENTAÇÕES
}

\author{
Ana Julia PACHECO ${ }^{1}$ \\ Karla Leandro RASCKE ${ }^{2}$
}

RESUMO: O presente artigo propõe discutir um conjunto de notícias sobre a Guerra de Biafra (1967-1970) presentes nas páginas da revista Veja. Nosso objetivo cunhase em examinar os sentidos políticos e retóricos do periódico sobre uma das maiores tragédias humanas do século XX ocorrida no sudoeste do território da Nigéria. O conflito emancipou, pelo povo igbo, a República do Biafra, cuja existência efêmera encharcou a comunidade internacional de imagens que registravam a miséria e as mazelas provocadas pela guerra. No Brasil, Biafra fez-se presente em revistas semanais e jornais diários, oriundos do processo de modernização da imprensa, que atuaram informando os acontecimentos nacionais e internacionais por meio da publicação de notícias imediatas e na formulação e intermediação de projetos de interesses públicos e governamentais. Para esse texto, enquanto fontes documentais, as autoras utilizaram os números publicados pela Revista Veja entre 1968 e 1970, contexto de acontecimentos da guerra. $\mathrm{O}$ acervo desse periódico encontra-se disponível gratuitamente no site da própria revista (www.veja.abril.com.br/acervo). As imagens e as narrativas veiculadas no periódico apontam um contexto de fome, violência e debates humanitários.

PALAVRAS-CHAVE: história; Biafra; Nigéria; Revista Veja; imprensa.

\footnotetext{
1 Universidade Federal do Rio Grande do Sul (UFRGS), Porto Alegre - RS - Brasil. Doutoranda no Programa de Pós-graduação em História. Universidade do Estado de Santa Catarina, Núcleo de Estudos Afro-Brasileiros da (NEAB/UDESC), Florianópolis - SC - Brasil. Pesquisadora associada. Professora de História da Rede de Educação do Estado de Santa Catarina (SED/SC). ORCID: https://orcid.org/0000-0001-5800-4862. anajulia.hp@gmail.com

2 Universidade Federal do Sul e Sudeste, Faculdade de História, Marabá - PA - Brasil. Docente no Programa de Pós-Graduação em História e do ProfHistória. Editora da Escritas do Tempo. Presidente da Comissão Permanente para Diversidade, Heteroidentificação e Etnicidade. Pontifícia Universidade Católica, São Paulo - SP - Brasil. Doutora em História Social. ORCID: https:/orcid.org/0000-0003-0580-3737. karlaleandro@gmail.com
} 


\title{
BIAFRA IN THE PAGES OF THE REVISTA VEJA (1968-1970): BETWEEN IMAGES, SPEECHES AND REPRESENTATIONS
}

ABSTRACT: The present article proposes to discuss a set of news about the Biafra War (1967-1970) on the pages of Veja magazine. Our goal is to examine the political and rhetorical meanings of the periodical about one of the greatest human tragedies of the 20th century occurred insouthwest of Nigeria. The conflict has emancipated, by the Igbo people, the Republic of Biafra, whose ephemeral existence drenched the international images community that registered the misery and the ailments caused by the war. In Brazil, Biafra was present in weekly magazines and daily newspapers, from the modernization process of the press, who acted to inform national and international events through the publication of immediate news and in the formulation and intermediation of projects public and governmental interests. For that text, as documentary sources, the authors used the numbers published by Veja magazine between 1968 and 1970, context of war events. The collection of this journal is available free of charge on the magazine's website (www.veja.abril.com.brlacervo). The images and narratives published in the journal point to a context of hunger, violence and humanitarian debates.

KEYWORDS: history; Biafra; Nigéria; Veja magazine; press.

\section{Introdução: Biafra, a história de uma guerra}

\begin{abstract}
Disseram-me que os biafrenses lutavam como heróis, mas agora sei que os heróis lutam como os biafrenses. Chimamanda Ngozi Adichie Meio Sol Amarelo ${ }^{3}$
\end{abstract}

Considerado um dos conflitos mais violentos da África contemporânea, a Guerra Civil da Nigéria ou a Guerra de Biafra (1967-1970) constituiu-se, de modo geral, em um movimento separatista da região do sudoeste da Nigéria, território que englobava os principais poços de petróleo do país no Delta do Níger.

\footnotetext{
3 A Guerra de Biafra consta no enredo de diferentes escritores africanos, principalmente entre os nigerianos. Em Half of a Yellow Sun (2006), Chimamanda Adichie narra, por meio de uma intermediação com os tempos da narrativa, a história de cinco personagens, que no decorrer de toda a década de 60, lutaram a favor da construção de Biafra e contra a opressão do exército nigeriano no contexto da Guerra de Biafra. O romance possui trinta e sete capítulos, os quais estão distribuídos em quatro partes estruturalmente interdependentes. Ver mais em: Freitas (2012). Também no âmbito da análise literária, em conexões História-Literatura, uma monografia de conclusão de curso em História suscita reflexões, a saber: Chan (2017).
} 
As tensões regionais recorrentes desde a independência da Nigéria, alcançada em 1960, levaram os esforços de oito milhóes de Ibos, sob a liderança do General Chukwuemeka Odumegwu Ojukwua ${ }^{4}$, a proclamar a República Independente de Biafra. Seguiu-se, assim, a guerra civil, cujo sonho nacionalista foi refreado pela força federal nigeriana contra a desintegração territorial e política do país ainda recém independente.

O conflito levou a perdas devastadoras envolvendo a morte de mais de três milhóes de pessoas em combate ao longo do período em que se sucedeu. Enquanto uma nação independente, Biafra foi reconhecida por Gabão, Haiti, Costa do Marfim, Tanzânia e Zâmbia; por outro lado, outros países não deram reconhecimento oficial, mas providenciaram algum tipo de assistência e apoio. Embora o movimento tenha sido levantado pelo povo Ibo, a posição estratégica do Biafra revela motivos políticos e econômicos para tal inflexão, com envolvimento, inclusive, direto de "potências externas" (MELOS; MEROLA, 2014, p.49).

A trajetória da independência da Nigéria é marcada por movimentos nacionalistas organizados nos anos de 1930 que incentivavam os nigerianos a ter maior participação no governo até então sob o domínio do protetorado britânico. Fomentado a partir da grande depressão econômica que alcançou a Nigéria nos anos 1930 e 1940, esses movimentos nacionalistas tinham como expoentes africanos educados em moldes e princípios europeus, dado que a educação formal era uma incumbência britânica. Dentre os mais importantes nomes, estava Nigerian Youth Movement (NYM), que contribuiu ativamente no processo de independência, conquistada apenas em 1960.

Embora a independência fora garantida, a economia nigeriana ainda permanecia dependente da antiga metrópole e o novo país estava dividido em vários níveis e marcadamente ausente de um projeto de nação. Desse modo, o clima de instabilidade ponderava sobre o novo Estado composto por três grandes grupos étnicos: os Hausan-Fulani (norte), Yoruba (sudoeste) e os Igbo (sudeste), somado ainda a uma série de outras comunidades menores, endossadas por diferentes identidades regionais, mais determinantes do que uma ideia de identidade nacional.

Foi essa instabilidade que desencadeou a guerra civil, experienciada na segunda metade da década de 1960 , onde a região sudeste tentou separar-se da

\footnotetext{
4 Chukwuemeka Odumegwu Ojukwu (1933-2011) foi um oficial militar e político nigeriano, tendo servido como governador militar da Região Leste da Nigéria em 1966. Foi líder separatista da República de Biafra de 1967 a 1970 e político nigeriano de 1983 até 2011, quando morreu aos 78 anos, na Inglaterra, vitimado por problemas de saúde.
} 
Nigéria para estabelecer o Estado soberano de Biafra (FALOLA; HEATON, 2008). O conflito que ocorreu oficialmente entre 6 de julho de 1967 e 15 de janeiro de 1970 "tinha como opositores o Governo Federal Nigeriano e o território da Nigéria Oriental, que havia se tornado independente em 31 de maio de 1967, autoproclamando-se República de Biafra" (RIBEIRO, 2019, p.2), depois de inúmeros massacres ocorridos no ano de 1966.

O conflito globalizado foi tido como uma "guerra mundial em miniatura", embora sem intervenção do fator nuclear. Biafra tinha o apoio dado por França e Portugal (mesmo que nunca tenham reconhecido a nação como independente), a ajuda material oferecida por Israel, e o também o suporte dos rodesianos brancos. Por outro lado, a Nigéria Federal era apoiada pelos britânicos, pelo Egito (também um ex-protetorado britânico), que cedeu pilotos para as missóes de aviação, e ainda favorecidos pela atitude da Organização pela Unidade Africana (OUA), adepta à manutenção da integridade territorial da Nigéria (MAZRUI, 2010).

A presença dos países do bloco soviético também desempenhou um importante papel no desenrolar da guerra do Biafra, sendo que o governo federal beneficiou-se com a relevante ajuda militar soviética, a qual contribuiu para a vitória do regime de Lagos. Após a guerra, o país continuou a receber significativa ajuda militar da URSS, sob a forma de equipamentos e no que tange à formação (THIAM; MURILA, 2010).

A Guerra de Biafra ganhou destaque na imprensa mundial, que disseminou fotografias emblemáticas registrando a tragédia do evento. Enquanto primeiro conflito pós-colonial, Biafra gerou uma onda transnacional de preocupação humanitária, envolvendo órgãos internacionais, instituiçóes não governamentais e organizações religiosas.

In the summer of 1968, contemporaries around the globe witnessed the emergence of a new 'third world' icon: the 'Biafran babies'. Readers and audiences in the west in particular were confronted with photographs of starving children in the secessionist Republic of Biafra, which made headlines for months. For various commentators, the Biafran crisis marks the onset of a new age of humanitarian catastrophe broadcast by modern media. According to Michael Ignatieff, the 'age of televised disaster' began with the Biafran war. (HEERTEN; MOSES, 2014, p.176) 5 .

\footnotetext{
5 Tradução das autoras: "No verão de 1968, contemporâneos ao redor do globo testemunharam o surgimento de um novo ícone de "terceiro mundo": os 'bebês biafrenses'. Os leitores e o público no Ocidente em particular foram confrontados com fotos de crianças famintas na secessionista República de Biafra, que ganhou as manchetes por meses. Para vários comentaristas, a crise de Biafra marca o início de uma nova era de catástrofes humanitárias
} 
No Brasil, o conflito também alcançou espaço na mídia impressa, em especial nas revistas semanais e nos jornais diários. O amplo processo de modernização da imprensa passaram a atuar informando os acontecimentos nacionais e internacionais, por meio da publicação de notícias imediatas e na formulação e intermediação de projetos de interesses públicos e governamentais. Nesse sentido, o presente artigo ${ }^{6}$ propóe discutir o conjunto de notícias sobre a Guerra de Biafra presentes em um periódico de circulação impressa, depois online, a Revista Veja.

Num primeiro momento, discutimos acerca do lugar da Imprensa e do conceito de Representaçóes, entendendo-o como uma categoria fundamental para analisar e pensar um veículo da mídia impressa, como é a Revista Veja. Em seguida, examinamos e problematizamos as notícias que cobrem os eventos ocorridos durante o conflito pela revista. Concordamos com Ribeiro (2019) no sentido de que a imprensa internacional trouxe imagens e representaçóes de grande proporção sobre os conflitos e a miserabilidade ocasionada em virtude da guerra.

Para o desenvolvimento desta investigação foram consultadas integralmente as ediçốes da Revista Veja de no 1 do ano de 1968 à edição no 121 do ano de 1970 através do seu Acervo Digital ${ }^{7}$, que somam 12 notícias respetivamente 9 na seção internacional, 1 na seção religião, 1 na seção humor e 1 correspondente a capa e sua reportagem. Dada a ausência de assinaturas nas sessóes e nas notícias, compremos as narrativas sobre Biafra presentes nas páginas de Veja como parte da linha editorial vinculada ao posicionamento institucional do órgáo.

A seleção dessa documentação ocorreu durante pesquisa de mestrado de Ana Julia Pacheco, quando naquele momento pesquisava o periódico como fonte histórica para compreensão das representaçóes sobre o Apartheid

transmitida pela mídia moderna. De acordo com Michael Ignatieff, a "era do desastre televisionado" começou com a guerra de Biafra." (HEERTEN; MOSES, 2014, p.176).

6 Este texto faz parte de um estudo efetuado após o desenvolvimento da dissertação de mestrado (2018) da autora Ana Julia Pacheco no Programa de Pós-graduação em História da Universidade Federal do Rio Grande do Sul que investigou a presença africana, e especificamente, o Apartheid, nas edições da Revista Veja de 1968 a 1985. Oportunamente, envolveu diálogos em forma de estudos e questões reflexivas conectados à pesquisa em andamento da autora Karla Leandro Rascke, intitulada "O perigo da História única": o ensino de História da África nas universidades públicas do Norte do Brasil, com início em 2018.

7 Disponível em http://veja.abril.com.br/acervodigital. O Acervo Digital da Revista Veja está no ar desde 2008 com acesso livre e gratuito a todas as suas edições, desde a primeira publicada em 11 de setembro de 1968. O projeto para a realização do Acervo Digital teve patrocínio do Bradesco e foi desenvolvido pela Veja em parceria com a Digital Pages. O acervo apresenta as edições em ordem cronológica e conta com um avançado sistema de busca desenvolvido especialmente para o periódico. Ver mais em https:/www.ufrgs.br/blogdabc/revista-veja-disponibilizatodo-o-seu/. Informamos que atualmente, 2020, o acervo da Revista não está mais acessível gratuitamente, sendo viável apenas para assinantes. 
(PACHECO, 2018), em abordagens que culminaram em sua dissertação de mestrado. Oportunamente, diante de parceria existente há mais de uma década com Karla Leandro Rascke, desde vínculos estabelecidos no Núcleo de Estudos Afro-Brasileiros da Universidade do Estado de Santa Catarina, sob a coordenação do professor Paulino de Jesus Francisco Cardoso, as autoras envidaram esforços em estabelecer uma narrativa que permita interpretar como a Revista Veja produziu imagens e perspectivas sobre a Guerra Civil em Biafra durante o próprio desenrolar do conflito.

\section{Mídia, impressos e a Revista Veja: na trama das representações}

Parte constitutiva dos fenômenos sociais que marcam memórias e narrativas históricas contemporâneas, os meios de comunicação de massa, em especial, a mídia jornalística impressa, apresentam-se, como uma das instâncias discursivas organizadoras do social que, ao narrar e atribuir significados, articula e angaria legitimidade como uma das estruturas definidoras do que deve ser lembrado ou esquecido.

Nascido oficialmente no início do século XIX, o jornalismo brasileiro emergiu por meio dos primeiros jornais diários publicados em 1808, quando da vinda da família real portuguesa. Posteriormente, surgiram as revistas e os almanaques, com publicaçóes mais elaboradas e periodicidade mais longa, voltadas para temas específicos.

Essa emergência de produção midiática abriu um campo de possibilidades potencializadas para a compreensão histórica da importância do mercado de novas publicaçóes jornalísticas na articulação de projetos políticos que promoveram e evidenciaram engajamentos políticos e tensóes culturais. No caso de Biafra, a mídia impressa e televisiva produziu interpretaçóes. A imprensa internacional expôs as atrocidades em Biafra, não isenta de interesses e concepções, mas trouxe à tona as mazelas da guerra. "Os massacres de 1966 foram largamente expostos, porém as vítimas relatadas eram sempre os igbos. Acontece que integrantes das minorias étnicas efik, ijaw, ogoja, ibibio e outros, foram igualmente massacrados no norte." (CHAN, 2017, p.32).

Nesse sentido, o conceito de representação para pensar as narrativas sobre a Guerra de Biafra, em Veja, nos parece central para conduzir a análise da fonte impressa. Instrumento essencial na trajetória da História Cultural ${ }^{8}$, que tem por

\footnotetext{
8 Em 2006 numa edição comemorativa de vinte anos do Programa de Pós-Graduação em História da UFRGS a Revista Anos 90 traz no ensaio de Sandra Jatahy Pesavento uma reflexão em torno dos estudos, pesquisas e reflexões que envolvem as temáticas de Cultura e Representação imersos no programa. O entendimento da cultura mudou ao
} 
objetivo identificar o modo como em diferentes lugares e momentos uma determinada realidade social é construída, pensada e dada a ler, as representaçóes do mundo social, segundo Roger Chartier (2002), são determinadas pelo interesse dos grupos que a forjam.

Para o autor, sempre aspirando a universalidade de um diagnóstico fundado na razão, as percepçôes do social não são de forma alguma discursos neutros, mas produzem estratégias e práticas incessantemente, que tendem a impor uma autoridade à custa de outros, por elas menosprezados, e a legitimar um projeto reformador ou a justificar, para os próprios indivíduos, suas escolhas e condutas. Chartier (2002) aponta que as representaçóes devem ser sempre colocadas num campo de concorrências e de competiçóes, cujos desafios se enunciam em termos de poder e dominação; igualmente deve se pensar o relacionamento dos discursos proferidos com a posição de quem os utiliza.

Em contrapartida, o conceito de representação, segundo Stuart Hall, ancorado em perspectiva dos Estudos Culturais, tem ocupado um novo e importante lugar no estudo da cultura, aproximando os sentidos de linguagem à cultura.

La representación es una parte esencial del proceso mediante el cual seproduce el sentido y se intercambia entre los miembros de una cultura. Pero implica el uso del lenguaje, de los signos y las imágenes que están en lugar de las cosas, o las representan. (HALL, 2010, p.447).

Para Hall (2010), portanto, a representação é a produção de sentido através da linguagem, sendo a cultura o compartilhamento de significados, e, por meio da linguagem, esses significados são produzidos e trocados onde as coisas ganham sentido. Os significados, segundo ele, constroem sentidos sobre quem somos e como elaboramos pertencimentos, produzidos e trocados em todas as interaçóes sociais e pessoais que fazemos parte, incluindo, nesse sentido, a mídia, que promove a circulação e produção de significados, através da linguagem.

Numa abordagem discursiva para a compreensão da representação, Hall (2010) acredita que no discurso podemos perceber não só como a linguagem e a representação produzem significados, mas também como um discurso parti-

\footnotetext{
longo dos anos, em que a aproximação dos historiadores com os antropólogos levou ao encontro da concepção de cultura como um conjunto de significados partilhados. Logo, a cultura é vista como uma produção social e histórica a se expressar, através do tempo, em valores, modos de ser, objetos, práticas. Ela é ainda uma forma de leitura e tradução da realidade que se mostra de forma simbólica, ou seja, admite-se que os sentidos conferidos às palavras, às coisas, às ações e aos atores sociais apresentam-se de forma cifrada, portando já um significado e uma apreciação valorativa (PESAVENTO, 2006, p.49).
} 
cular articula-se ao poder, regulando e construindo subjetividades, redefinindo a maneira como as coisas sáo representadas e compreendidas.

A Revista Veja, na qualidade de periódico, ou seja, uma fonte jornalística, é compreendida e trabalhada nesse texto metodologicamente enquanto um instrumento estratégico para a compreensão da vida contemporânea. Imbricado às complexidades do mundo social, as práticas do fazer jornalístico estão relacionadas ao cotidiano, integrante de um sistema comunicacional, pensado como uma das práticas culturais.

Tal como força ativa da vida moderna, o impresso compóe mais do que um dispositivo de registro dos acontecimentos, atuante na constituição de nossos modos de vida, perspectivas e consciência histórica, por meio da produção de hegemonias, dimensão de distintas temporalidades, diagnósticos do presente, afirmação de memórias de sujeitos, de eventos e de projetos, com as quais pretende articular as relaçóes presente/passado e perspectivas de futuro.

A Revista Veja, lançada em setembro de 1968, e atualmente a mais consumida revista semanal de informação do Brasil, surgiu com intuito de trazer para os leitores eventuais informaçóes sobre os fatos ocorridos no país e igualmente fora dele. Nas palavras do primeiro editor, Victor Civita,

[...] o Brasil não pode mais ser o velho arquipélago separado pela distância, o espaço geográfico, a ignorância, os preconceitos e os regionalismos: precisa ter informaçáo rápida e objetiva a fim de escolher rumos novos. Precisa saber o que está acontecendo nas fronteiras da ciência, da tecnologia e da arte no mundo inteiro. Precisa acompanhar o extraordinário desenvolvimento dos negócios, da educação, do esporte, da religião. Precisa, enfim, estar bem informado. E este é o objetivo de Veja. (VEJA, n.1 01/09/68, p.3).

A partir da condição de revista de informação com periodicidade semanal, ela elabora sínteses dos acontecimentos, organizando-os em narrativas próprias, buscando explicar e atribuir sentido à realidade a partir de um espaço maior de tempo. Todavia, seu tempo na narrativa jornalística funciona para dar a ler, conhecer e explicar diferentes temas e, mais importante, funciona para legitimar determinada forma de conceber o mundo e partilhar projetos de futuro (SILVA, C., 2014).

O periódico apresenta temas do cotidiano da sociedade brasileira como economia, política, diplomacia, transformaçóes e conflitos territoriais, ecologia, saúde, tecnologia, religião, cultura, artes, entre outros, apresentando algumas seçóes 
fixas sobre cinema, música, literatura, entrevista. Os textos são escritos em sua maior parte por jornalistas, porém, nem todas as seçôes são assinadas. Tornandose um importante veículo de produção de informação no mercado editorial do país na década de $1970^{\circ}$, sua criação, pela Editora $A b r i l$, situa-se num contexto de consolidação do mercado de bens simbólicos, ocorrido a partir dos anos 1960.

No âmbito de seus eventos e personagens, o cenário internacional ganha espaço no periódico. Os países e as populaçóes do continente africano, nesse mesmo momento, sob transformaçôes políticas e econômicas decorrentes dos processos de independência política, tornam-se pauta da mira jornalística de Veja. Há um destaque à África do Sul, cujas notícias estão relacionadas às implicaçóes do regime político racista do Apartheid, que vigorava no país, e os possíveis laços diplomáticos, políticos e econômicos entre Brasil e os países da África pensados e articulados efetivamente em meados de 1970.

Nesse sentido, entendemos particularmente a Veja, bem como as demais revistas de circulação nacional, como parte inseparável das narrativas sociais que guiaram a compreensão dos processos culturais e políticos no Brasil contemporâneo. Trata-se de compreender o periódico enquanto produçáo conectada com a vida cotidiana, tornando-se "impossível entender a dinâmica dos conflitos sociais e das disputas políticas nas sociedades contemporâneas sem levar em conta o papel dos meios de comunicação de massa" (MIGUEL, 2016, p.7).

Vejamos, na sequência, como a revista interpretou e publicizou os acontecimentos relacionados à Guerra de Biafra.

\section{"A primeira guerra moderna da África Negra": Biafra nas páginas da Revista Veja}

A primeira notícia do conflito está localizada na segunda edição da Revista Veja, datada de nove de setembro do ano 1968, na seção internacional intitulada "Biafra, o apocalipse". Estampa boa parte de duas páginas, com imagens de uma ossada humana e um corpo destroçado, ambos no chão, sob a legenda: "Agora não há nem mesmo tempo para enterrar os mortos. Eles apodrecem nos cami-

\footnotetext{
9 Segundo Villalta (2002), a publicação da Abril conhece logo no início de sua circulação o êxito dos quase 700 mil exemplares vendidos de seu primeiro número, e anos subsequentes de fracasso (de 1968 a 1972). Como informa a autora, em 1968, o público consumidor de revistas estava acostumado com dois tipos de publicações: as semanais ilustradas, representadas por Manchete e o modelo de revista de economia e política da internacional Visão. Veja nascia com uma proposta diferente mediante aos padrões brasileiros, entretanto, o modelo trazido diretamente dos Estados Unidos decepcionou os anunciantes, fazendo com que a consolidação da revista junto ao mercado consumidor levou alguns anos para acontecer.
} 
nhos de Biafra, últimas testemunhas de uma das maiores tragédias dos tempos modernos." (VEJA, n. 2, 25/09/68, p.59).

Expondo a ameaça ao povo biafrense feita pelo Coronel Benjamin Adekunle, a notícia evidencia um dos comandantes militares da Federação da Nigéria, e segue trazendo dados da guerra, especialmente das baixas em Biafra, apontando o apoio inglês e egípcio ao governo nigeriano de Yakabu Gowon e assinalando que os biafrenses, apontados por Veja como "rebeldes", estavam “[...] completamente isolados do resto do mundo, mulheres e crianças morrem de fome" (VEJA, n. 2, 25/09/68, p.58). A notícia é finalizada com um destaque da fala do embaixador de Biafra - Lois Mbanefo -, na conferência de paz, em Adis Adeba, demostrando a resistência de Biafra.

Figura 1 - Imagens da reportagem "Biafra, o apocalipse"

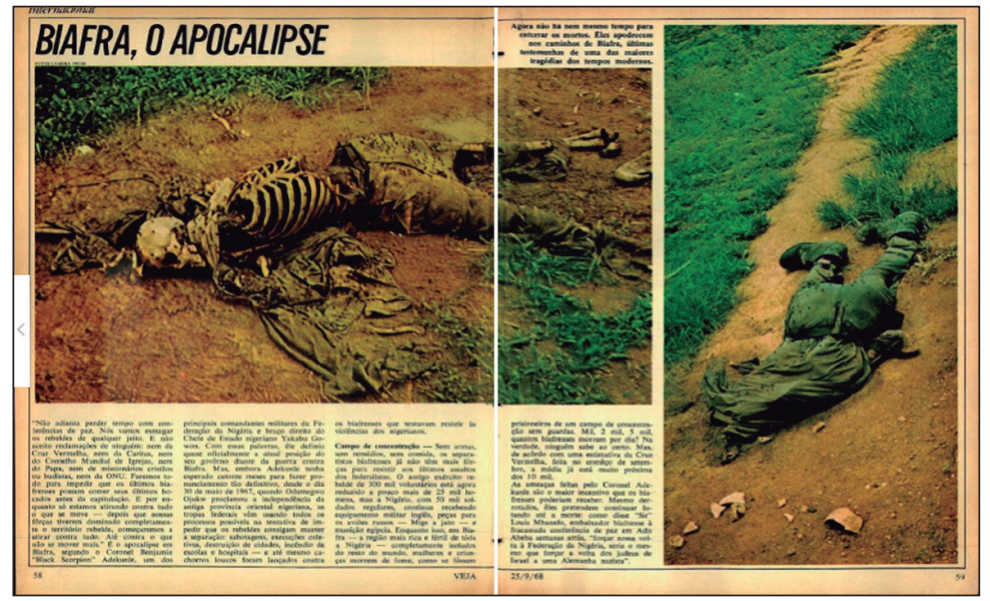

Fonte: Veja, n.2, 25/09/68, p.58-59

A matéria tem imagens que ocupam quase as duas páginas e causam impacto dada a evidência visual da guerra. Além disso, o texto escrito destaca a violência e o horror da guerra com cenas terríveis que envolviam a fome e as doenças decorrentes dos conflitos alcançaram o mundo. Percebemos que a matéria póe em questão o enfraquecimento dos "separatistas", pois em termos numéricos suas baixas eram visíveis, ao passo que a Nigéria continuava a receber armamento e equipamentos militares de seus apoiadores.

Biafra aparece novamente na edição de número 7 , também na seção internacional, numa reportagem de cinco páginas denominada "O horror sem fim de Biafra”, junto a imagens de corpos no chão e crianças biafrenses sob a legenda 
"Amaldiçoados por toda a África, abandonados pelo resto do mundo, os guerreiros de Biafra continuam sua resistência desesperada contra a morte" (VEJA, n.7, 22/10/68, p.34-35).

A notícia inicia descrevendo o cenário da guerra em Biafra, destacando, numa narrativa trágica a situação de milhares de crianças africanas, "[...] em seus corpos deformados e cérebros confusos” (VEJA, n.7, 22/10/68, p.35). A guerra de Biafra foi explicada por Veja fundamentalmente como uma "questão de tribos", evidenciada por uma rivalidade "entre irmãos" no "continente negro". Com uma ênfase nos detalhes de corpos em decomposição, o cenário aparece destroçado, e o olhar construído pela manchete destaca uma Biafra "amaldiçoada por toda a África”. Na percepção da revista, esse conflito seria "o maior e o mais sangrento da história da África” (VEJA, n.7, 22/10/68, p.35).

A retórica de cunho racial e pejorativo permeia toda a narrativa que contextualiza o conflito em Nigéria para seus leitores: "Os Ibos de Biafra ingressaram tardiamente no mundo moderno, emergindo da selva na década dos 30 ” (VEJA, n.7, 22/10/68, p.36). Biafra aparece como possível estímulo para outras "tribos inquietas” em nações africanas darem início a sua própria secessão, como Etiópia, Quênia, Daomé e Sudão citadas pelo periódico. Evidenciando o conflito como "Questão de tribos", não apenas perpetua um imaginário colonial, mas reforça que os problemas seriam decorrentes de conflitos internos, sequer trazendo à cena as décadas de colonialismo britânico, por exemplo.

A OUA foi citada como um órgão de esperança falida para Biafra cuja última reunião da cúpula aprovou uma resolução solicitando aos "rebeldes" que colaborassem com as autoridades federais nigerianas, igualmente a comunidade internacional denunciada como "cumplices das mortes em massa, por inanição, na Nigéria” (VEJA, n.7, 22/10/68, p.37).

Em seu final, o artigo destaca a "amarga verdade", já conjecturando a derrota dos biafrenses frente aos soldados federais e apontando o erro do povo Ibo em presumir que a Nigéria não poderia continuar sem eles. Nos dizeres da revista: "Os Ibos poderão descobrir, agora, que eles precisam mais da Nigéria, do que a Nigéria deles” (VEJA, n.7, 22/10/68, p.38). 
Figura 2 - Imagens da reportagem "O Horror sem fim de Biafra”

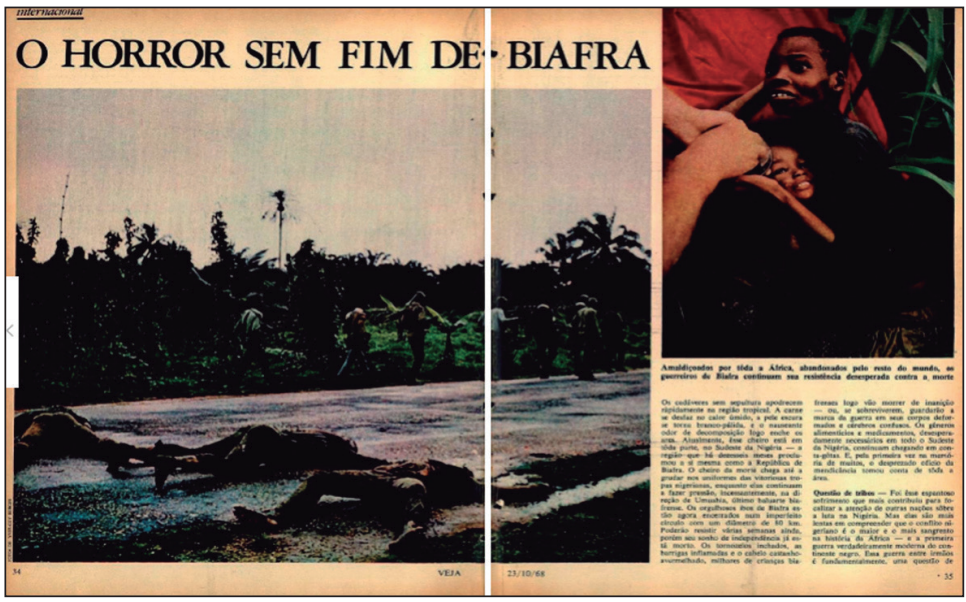

Fonte: Veja, n.7, 22/10/68, p.34-35.

"Nigéria: O General De Gaulle entra em ação e consegue reavivar uma guerra que estava chegando ao fim" é o título da notícia seguinte, presente na seção internacional de Veja em sua décima primeira ediçáo. $\mathrm{O}$ artigo trouxe uma pequena imagem acima do texto de soldados em ação com a legenda "Soldados biafrenses em combate: entra em cena De Gaulle, a guerra renasce" (VEJA, n.11, 20/11/68, p.39), narrando a ajuda francesa personificada no presidente Charles de Gaulle ao exército Biafrense e o descontentamento do governo nigeriano com o ato francês. Junto a esse apoio, a revista também aponta o papel das naçóes de Costa do Marfim e Gabão (ex-colônias francesas) para o auxílio no descarregamento de armas e suprimentos até o território de Biafra.

$\mathrm{O}$ apoio e a interferência internacional na guerra civil nigeriana continuaram presentes na notícia seguinte sobre o conflito na edição de número 12. "Nigéria: os russos já estão chegando, com rublos e atençôes" (VEJA, n.14 11/12/68, p.44) destacou o apoio soviético ao governo da Nigéria, com a venda de modernos equipamentos militares e consequentemente a intensificação nas relaçóes comerciais entre russos e nigerianos. $\mathrm{O}$ artigo trouxe apenas uma imagem do líder nigeriano com a legenda "O presidente Gowon: olhos abertos" (VEJA, n.14 11/12/68, p.45) e descreveu as relaçóes entre Nigéria e Rússia.

$\mathrm{Na}$ trigésima edição, de fevereiro do ano seguinte, em sua seção internacional, a Revista Veja noticiou "A ressurreição de Biafra", destacando o cotidiano de resistência dos biafrenses atrelado aos "inteligentes e trabalhadores" Ibos. Os perspicazes triunfos ganharam destaque em parte significativa do artigo, que 
narra as operaçóes e estratégias de Biafra para o recebimento de armamento e muniçóes estrangeiras, especialmente francês, e alimentos que mantiveram os biafrenses ativos.

As imagens contempladas seguem mostrando o cotidiano de guerra dentro do território de Nigéria, com imagem focando numa criança em situação de miséria. A Veja aponta uma melhora na situação de Biafra, sua "ressureição" através da resistência, entretanto, continua eminente em seu olhar a derrota dos separatistas. "Assim, entre um expediente e outro, Biafra continua vivendo [...]. Mas sob quaisquer circunstâncias, é difícil imaginar uma saída feliz para a primeira guerra moderna da África Negra” (VEJA, n. 30, 02/04/69, p.37).

Figura 3 - Imagens da reportagem "A ressurreição de Biafra"

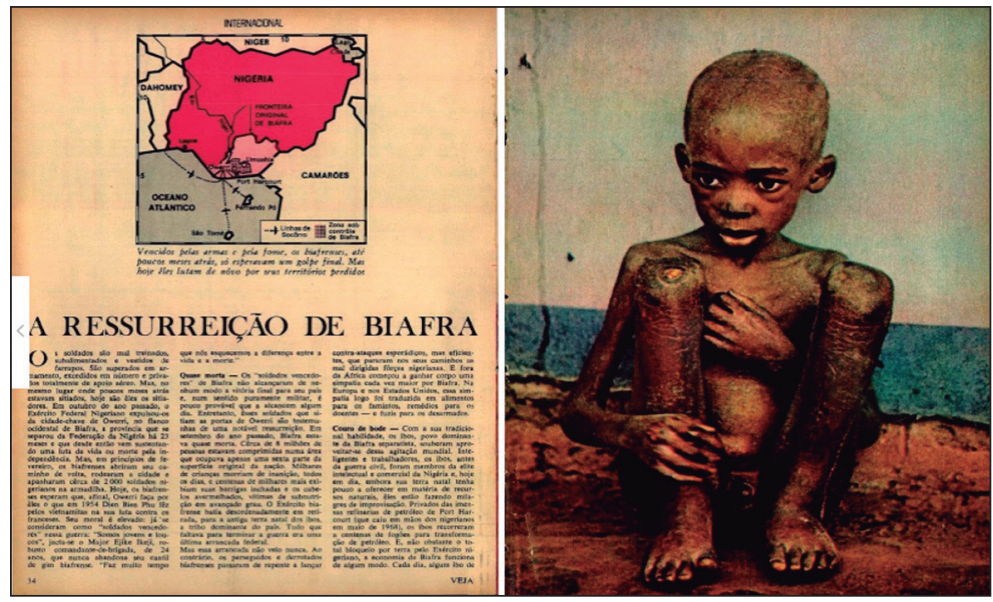

Fonte: Veja, n.30, 02/04/69, p.37-38.

Biafra volta a ser noticiada na edição de número 41, na seção internacional do periódico, em junho de 1969, no artigo intitulado "O Conde ataca novamente", com foco no apoio do "aventureiro" sueco Carl Gustav von Rosen, que passou a treinar a comandar a nova Força Aérea de Biafra vitoriosa nas últimas semanas de guerra.

A narrativa descreve as estratégias adotadas pelo Conde, o que estaria possibilitando uma reviravolta na guerra em favor de Biafra, e o destaque no incentivo humanitário que levou o comandante a ajudar os biafrenses. Em seu número 47 publicado no final de julho, Veja contempla, na capa de sua edição, parte de uma imagem de crianças biafrenses em meio a outras imagens que representam importantes acontecimentos do ano de 1969, cujo destaque prin- 
cipal refere-se à primeira viajem do homem à lua, sob título "Armstrong: que ganhamos com a lua?"

A capa traz a reportagem intitulada "Que futuro traz essa lua?" e embaixo as seguintes reflexóes, nas legendas que abrem o artigo: "Os cientistas falam em uma nova era. Os astronautas voltam e encontram a mesma terra com suas contradiçóes [...]"; e "O homem pula com jatos na sola, como fará na lua e nas estacoes orbitais. Mas como pular sobre as misérias deste planeta? [...]” (VEJA, n.47, 40/07/69, p.31).

Dividido em sete partes, o artigo narra a trajetória e as expectativas do projeto Apolo 11 que levou a primeira vez o homem à lua. Biafra e as demais naçóes colocadas nas imagens que cobrem o capacete do comandante Neil Armstrong não são citadas ao longo da reportagem, ficando apenas na capa da edição, provavelmente, por ser tema recorrente daqueles anos.

Figura 4 - Imagens da capa "Armstrong: que ganhamos com a lua?"

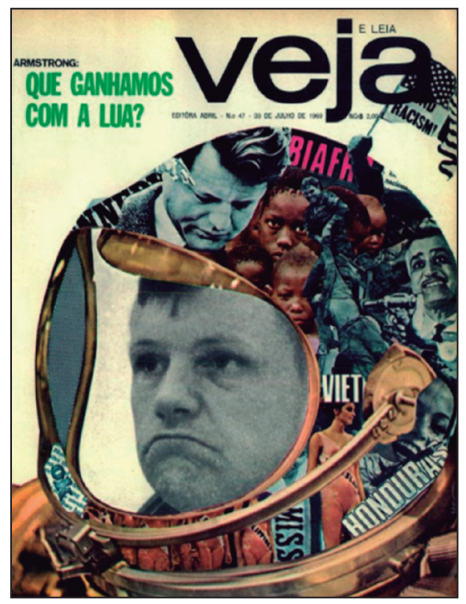

Fonte: Veja, n.47, 40/07/69

Na edição seguinte, Biafra é tema da seção Religião da revista que tem como título "Biafra náo aceitou a paz do papa: Mas houve alegria em Uganda e nos olhos do Presidente Obote" (VEJA, n.48, 06/08/69, p.24) e discute, por um lado, o fracasso do papa Paulo VI na sua missão em pôr um fim na guerra em Nigéria que, segundo Veja "Reuniu-se com eles separadamente, mas, quando tentou junta-los, Biafra não compareceu” (Idem). Por outro lado, enfatiza o sucesso da sua presença do religioso em Uganda na dedicação do santuário em memória dos 22 mártires de Uganda, queimados vivos em 1886 e canonizados 
em 1964. Estes 22 mártires foram assassinados entre os anos 1885 e 1887 . No dia 3 de junho de 1886, 12 deles foram queimados vivos junto a outros 20 anglicanos; 10 mártires foram esquartejados.

O periódico destaca as ideias do Papa, que deram certo em Uganda, no sentido de resolver os conflitos sem o apelo da violência, mas por meio de tratados razoáveis apoiados por instituiçóes internacionais: "[...] parecem não haver concordado os representantes biafrenses e nigerianos" (VEJA, n.48, 06/08/69, p.25). No entendimento do periódico, "Biafra não aceitou a paz do Papa", enquanto Uganda seria um "exemplo" de igreja "obediente e disciplinada" na África. A narrativa enfatizada por Veja reporta o tom à expansão do catolicismo no continente e a figura central da Igreja Católica naquele momento, o Papa Paulo VI enfatiza que "as relaçóes humanas não devem ser reguladas pela força" (VEJA, n.48, 06/08/69, p.25).

"Biafra: apenas uma boa intenção" tornou-se título do artigo da seção internacional da edição 54 de Veja que trata da discussão de um possível acordo de paz para Nigéria no encontro de quarenta líderes africanos da OUA reunidos em Addis Adebba. Criada com o objetivo de assegurar a independência recém-conquistada pelos países africanos, viabilizando a consolidação dos Estados Nacionais formados, a organização assumiu a responsabilidade primária pela manutenção da paz e segurança continentais (OUA, 1963). Nesse sentido, a discussão realizada em 1969 em Adis Adebba, pautando o conflito Nigéria-Biafra, envolvia preocupação dos Chefes de Estado com a solução desse conflito ${ }^{10}$.

A revista destaca a resistência de ambos os lados, para o Chefe de estado nigeriano, General Yakabu Gowon, o impensável acordo sem a rendição dos separatistas do governo; para o líder Biafrense Coronel Odumegwu Ojukwu, a inaceitável ideia de rendição proposta por Gowon. Enquanto isso Veja questiona: "Quantas pessoas morrem diariamente na guerra civil nigeriana? A fome ainda extermina as crianças de Biafra? E o soldados separatistas, continuam alimentando-se com carne de bode?" (VEJA, n. 54, 17/09/69, p.51).

Em dezembro de 1969, o fim da guerra civil em Nigéria e do sonho Biafrense é prenunciado no artigo "Biafra: o futuro morre aos poucos" na seção internacional da edição de número 58. A narrativa inicia dizendo que "O território cada vez menor de uma Biafra enfraquecida, desolada e quase derrotada vai sofrer agora, no fim da temporada de chuvas, mais uma ofensiva 'final'" (VEJA, n. 58, 17/12/69, p.58), anunciando o próximo encontro entre os representantes de Nigéria e Biafra em Addis Abeba para mais uma tentativa de acordo de paz.

\footnotetext{
${ }^{10}$ Para maiores informações a respeito da OUA, indicamos consultar as seguintes obras: Cardoso (2018); Joilson Silva (2013).
} 
A notícia é carregada de uma imagem com um soldado morto sob a legenda "Soldados de Biafra: sem esperança".

Em 21 de janeiro de 1970, o periódico anuncia "Finalmente venceu a morte: com o fim de Biafra, a Nigéria consegue uma vitória que não é gloriosa: significa o quase total aniquilamento de uma raça" (VEJA, n.72, 21/01/70, p.30), que narra em quatro páginas os últimos confrontos e o fim do conflito no território nigeriano. Com expressóes como "ex-território de Biafra", a matéria retoma a tragédia da guerra e as mortes dela resultantes. Utilizando termos e adjetivos, o periódico destaca o conflito como "trágico pesadelo que abalou profundamente a consciência mundial” (VEJA, n.72, 21/01/70, p.30).

$\mathrm{Na}$ primeira parte do artigo, Veja descreve os últimos dias do cotidiano biafrense, a última operação do exército federal nigeriano, e a fuga do coronel Ojukw personificado como "a última esperança de Biafra”, que entregou o comando das tropas ao General Philip Effiong. Este, em vista da vitória evidente das forças Gowon, ordenou como chefe maior do Estado de Biafra a rendição dos soldados biafrenses.

Na segunda parte, com o título "Todos culpados na guerra do apocalipse", o periódico faz uma reflexão em torno das causas e acontecimentos do conflito, apontando a culpabilidade também nas interferências estrangeiras, e finaliza com a seguinte colocação:

Mas Biafra, embora derrotada, provou um fato importante: que uma nação negra, privada de apoio estrangeiro, pode sozinha e sem a ajuda de técnicos brancos para dirigir seus estados-maiores, para fazer funcionar ferrovias, telefones, rádios e televisões, resistir a uma formidável pressão militar econômica e diplomática. E a vitória - se é que a palavra pode ser usada - do governo central nigeriano não terá nenhuma solidez enquanto os problemas tribais não forem, pelo menos, encaminhados para uma solução. (VEJA, n.72, 21/01/70, p.33, grifo nosso).

A imagem que abre o artigo enfoca novamente o corpo morto de um soldado, com outras duas ao longo da narrativa que trazem os líderes comandantes a guerra sob as legendas "Ojukwu: lutou para criar Biafra, no fim teve de abandonar os seus irmáos" e "Gowon: lutou para defender a unidade da Nigéria, sem partilhas e divisóes” (VEJA, n.72, 21/01/70, p.32). Demais imagens são de crianças em situação de vulnerabilidade, numa delas com a legenda "Para o futuro, uma geração assustada, enfraquecida e certamente incapaz" (VEJA, n.72, 21/01/70, p.33). 
Figura 5 - Imagem da reportagem "Finalmente venceu a morte: com o fim de Biafra, a Nigéria consegue uma vitória que não é gloriosa: significa o quase total aniquilamento de uma raça”"

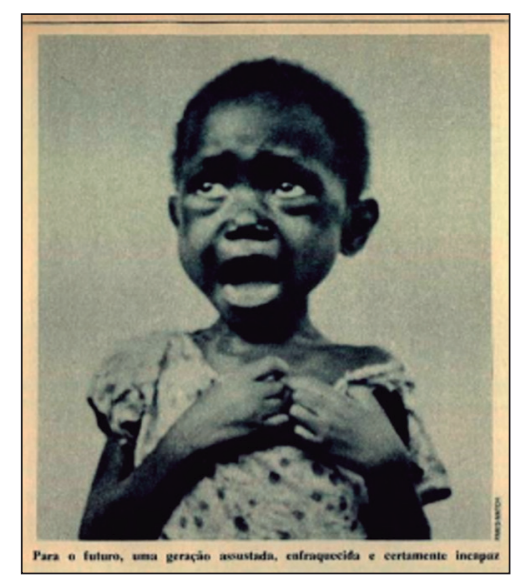

Fonte: Veja, n.72, 21/01/70, p.33

A última passagem de Biafra no periódico está na edição seguinte, de número 73, na seção Humor da revista, numa charge cujos personagens representam o acordo entre a União Soviética e o governo federal Nigeriano. Efetuado sob os territórios continentais africano e europeu abaixo de uma chuva de sangue, caracteriza os milhares de biafrenses mortos pelo governo federal nigeriano durante o conflito.

Figura 6 - Imagem da charge "Biafra"

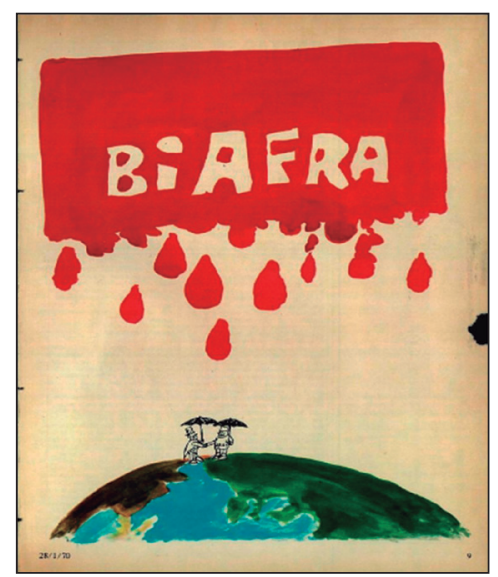

Fonte: Veja, n.73, 28/01/70, p.9. 


\section{Considerações Finais}

No Ocidente, a África foi vista através de uma violência discursiva colonial, produzida entre os séculos XVI e XX, condicionando a pensar as relaçóes do continente africano com o mundo atlântico a partir de perspectivas que a sugerem como um acidente geográfico, entre Oriente e o Ocidente, consolidando imagens-clichês que projetam informaçóes imprecisas e estereotipadas sobre a África (MENESES; SANTOS, 2010). Ao noticiar a Guerra de Biafra, constatamos a permanência desse viés narrativo presente na Revista Veja, que evidencia o aspecto trágico e violento em suas páginas, endossado por imagens de morte e mazelas da população biafrense causadas pelo conflito, num jornalismo descritivo do cotidiano de resistência do povo Ibo.

A derrota eminente é evidenciada em todos os artigos, que informam os dados de perdas principalmente de Biafra. Assim, o auxílio ou a intervenção estrangeira aparecem como solução de um conflito de uma população "negra" e "incapaz". A intervenção estrangeira, portanto, para Veja, aparece como um caminho possível para solucionar a situação da Nigéria, retirando o direito e a legitimidade dos próprios nigerianos à possibilidade de decidir e desenhar os rumos da sua nação.

Ao mesmo tempo, Veja também destaca a ausência de apoio à Biafra tanto por parte dos africanos quanto por parte da comunidade internacional, e, por conseguinte, questiona o completo silenciamento da posição brasileira sobre a guerra. A açáo de resistência dos Ibos ao longo do período de guerra se mostra como exceção de "uma nação negra" ao olhar de Veja.

Como é possível perceber, a narrativa do cotidiano de uma guerra pós-colonial africana é permeada por uma leitura racial e pejorativa em vários momentos tanto sobre as populaçóes nigerianas, quanto as populaçóes africanas. As diferenças culturais não são confrontadas pelo periódico e sim naturalizadas, alojadas dentro de uma enunciaçáo de matriz racial e biologicamente construído. Também utiliza adjetivos como "questão de tribos", "rivalidade entre irmãos" e "continente negro" para justificar os acontecimentos entre as populaçôes nigerianas, percepçôes estas do mesmo imaginário colonial que permitiu hierarquizar, dividir e animalizar as populaçôes africanas.

Essas consideraçôes dialogam com as discussôes resultantes de uma pesquisa de doutorado empregada por Anderson Oliva com o objetivo de identificar representaçóes mais recentes sobre o continente africano na revista Veja, entre as ediçôes que circularam nos anos de 1991 a 2006. De acordo com o pesquisador, o periódico atuou/atua na disseminação de ideias negativas sobre a África, 
refletindo olhares heterogêneos sobre os africanos e sobre suas realidades que permeiam no imaginário contemporâneo brasileiro ${ }^{11}$.

Considerando que os temas "Guerras, Massacres e Violência" e "Apartheid, Racismo e pós-apartheid” categorizados por ele, somam $43 \%$ por cento das publicaçôes, o autor explica que há uma iniciativa de atribuir as causas de um determinado ocorrido às rivalidades políticas entre "tribos" ou povos em conflito. Isso aponta também para as influências das açóes coloniais como um de seus elementos de origem.

Ao tratar das questôes políticas, as origens de mais uma "tragédia africana" transitam para os "conflitos tribais", revelando indícios de um olhar previamente construído sobre a África. "A ideia mais recorrente é a de que o continente desempenharia uma condição atípica de potencializador das atrocidades cometidas pela humanidade e das expressôes mais aviltantes da 'barbárie'." (OLIVA, 2008, p.157).

Contudo, Biafra é representada pela revista Veja através do desencadeamento e desenvolvimento da guerra civil que extinguiu o sonho de uma república.

Sua história demonstrou que a África estava incorporada ao mundo mais vasto das rivalidades planetárias. Mostrou também que a identidade africana, nascida da humilhação racial e da dominação estrangeira, não podia ser senão frágil e incerta. Sob o choque do colonialismo e do imperialismo, os africanos haviam tomado consciência do fato de representarem uma unidade diante dos opressores ocidentais. Contudo, uma solidariedade africana perene não podia fundar-se somente na experiência comum da exploração. Unir-se contra o opressor estrangeiro, era uma coisa; outra coisa, porém, era unir-se para pôr em marcha o desenvolvimento interno. (MAZRUI, 2010, p.15)

Colonialismo, imperialismo e racismo constituem tríade articulada e forjada para expropriação de riquezas, saberes e conhecimentos. Povos africanos,

\footnotetext{
${ }_{11}$ Conforme o autor, apesar de ter encontrado um número variado de temas e abordagens, nas páginas da Veja concentram-se matérias em torno de alguns assuntos associados a dois conjuntos de imagens tabuladas: as "leituras negativas" e as "leituras positivas". A primeira soma $62,5 \%$ das matérias, distribuídas nas seguintes categorias: "Guerras, Massacres e Violência”, 30 peças (22\% do total); "Apartheid, Racismo e pós-apartheid", 29 peças (21\%); "Tragédias, Fome e Doenças", 22 peças (16\%); "Africanos vistos como tribais/canibais/primitivos”, 4 peças (3\%); e a segunda corresponde a 37,5\% (51 peças) do total de reportagens, classificadas nas seguintes categorias: "Turismo, Esportes, Natureza", 20 peças (15\%); "Literatura, Cinema, Fotografia e Política", 19 peças (14\%); e "História, Paleontologia e Arqueologia”, 12 peças (9\%).
} 
indígenas e asiáticos constituem foco de atuação dessa tríade, mas mundialmente somos afetados pelo sistema de pensamento hegemônico ocidental. $\mathrm{O}$ eurocentrismo compóe vertente fértil na constituição de narrativas, imaginários e relaçóes de poder. Povos alijados de direitos e usurpados de suas riquezas sentem os efeitos das mazelas que essa combinação colonial perpetua. Conflitos armados, discursos veiculados e estereótipos arraigados têm produzido narrativas hegemônicas e violências.

\section{REFERÊNCIAS}

CARDOSO, N. C. F; OliveiRA, G. Z. de. Operaçóes de paz africanas: as experiências da OUA e da UA. Brazilian Journal of International Relations, Marília, v.7, n.2, p.334-370, maio/ago. 2018.

CHAN, M. A. Leituras sobre a Guerra de Biafra (1967-1970): as versões do conflito nos textos de história e literatura. Trabalho de Conclusão de Curso (Graduação em História) - Universidade de Brasília, Brasília, 2017.

CHARTIER, R. A história cultural: entre práticas e representaçōes. 2.ed. Lisboa: DIFEL, 2002.

FALOLA, T.; HEATON, M. M. A History of Nigéria. London: Cambrigde University Press, 2008.

FREITAS, J. F. A. de. Guerra de Biafra: as imagens de uma tragédia refletidas no espelho social. In: SILIAFRO, 1., 2012, Uberlândia. Anais [...]. Uberlândia: EDUFU, 2012. p.345-351.

HALL, S. Sin garantías: trayectorias y problemáticas en estudios culturales. Popayán: Envión Editores, 2010.

HEERTEN, L.; MOSES, A. D. The Nigeria-Biafra war: postcolonial conflict and the question of genocide. Journal of Genocide Research, Oxon, v.16, n.2/3, p.169-203, 2014.

MAZRUI, A. A.; WONDJI, C. (org.). História geral da África: África desde 1935. UNESCO, 2010. v.8.

MELOS, A. C.; MEROLA, V. As relaçóes bilaterais Brasil-Nigéria: um estudo de caso do período colonial aos dias de hoje. Revista Perspectiva, Porto Alegre, v.7, p.45-63, 2014. 
MENESES, M. P.; SANTOS, B. de S. (org.). Epistemologias do Sul. São Paulo: Cortez, 2010.

MIGUEL, L. F. História e política, cultura e mídia. In: LOHN, R. (org.). História das bancas de revista: um país impresso: entre representaçóes sociais e cultura políticas. Ponta Grossa: Editora Todapalvra, 2016. p.07-21.

OLIVA, A. R. Notícias sobre a África: representaçôes do continente africano na revista Veja (1991-2006). Afro-Ásia, [s. l.], n.38, p.141-178, 2008.

PACHECO, A. J. Apartheid nas páginas da Revista Veja (1968-1985). Dissertação (Mestrado em História) - Universidade Federal do Rio Grande do Sul, Porto Alegre, 2018.

PESAVENTO, S. J. Cultura e representaçóes, uma trajetória. Anos 90, Porto Alegre, v.13, n.23/24, p.45-48, jan./dez. 2006.

RIBEIRO, M. L. F. Biafra e a opinião pública internacional: como a cobertura jornalística influenciou os rumos da Guerra Civil Nigeriana. In: SIMPÓSIO NACIONAL DE HISTÓRIA, 30., 2019, Recife. Anais [...] Recife: ANPUH, 2019. Disponível em: https://www.snh2019.anpuh.org/resources/anais/8/1565318777_ ARQUIVO_ArtigoANPUH-Nacional.pdf. Acesso em: 30 ago. 2021.

SILVA, C. B. da. A invenção do futuro do Brasil: usos políticos do passado na Veja (1968-1978). In: AREND, S. (org.). Um país impresso: história do tempo presente e revistas semanais no Brasil 1960-1980. Curitiba: Ed. CRV, 2014. p.21-42.

SILVA, J. de A. M. A. Uniáo africana: desafios políticos e perspectivas de cultura no limiar do século XXI. Dissertação (Mestrado em História) - Pontifícia Universidade Católica de São Paulo, São Paulo, 2013.

THIAM, I. D.; MURILA, J. A África e os países socialistas. In: MAZRUI, A. A.; WONDJI, C. (org.). História geral da África: África desde 1935. UNESCO, 2010. v.8. p.965-1001.

VILLALTA, D. O surgimento da revista Veja no contexto da modernização brasileira. In: CONGRESSO BRASILEIRO DE CIÊNCIAS DA COMUNICAÇÃO, 25., 2002, Salvador. Anais [...]. Salvador: Intercom, 2002. p.01-15.

Recebido em: 20 de julho de 2020

Aceito em: 03 de outubro de 2020 